\title{
Humanismo Projetual: calçados para portadores de necessidades especiais no Brasil
}

\author{
Human Design: footwear for people with special needs in Brazil
}

\section{PASSOS, Verônica Thomazini I Mestranda em Moda}

Escola de Artes, Ciências e Humanidades da Universidade de São Paulo (EACH-USP)

vethomazini@gmail.com

\section{KANAMARU, Antonio Takao I Doutor em Design}

Escola de Artes, Ciências e Humanidades da Universidade de São Paulo (EACH-USP)

kanamaru@usp.br

\begin{abstract}
Resumo
Considerando o "humanismo projetual", proposto por Gui Bonsiepe (2011), este artigo discute a metodologia projetual no desenvolvimento de calçados para portadores de necessidades especiais, a partir do estudo de caso de uma criança portadora da Síndrome de Proteus. Com o objetivo de relatar as dificuldades da usuária na busca pelo calçado adequado, verificou-se como resultado, o prevalecimento do trabalho do artesão sobre o designer na projeção de calçados especiais no

\section{Abstract}

Considering the "Humanism projetual" proposed by Gui Bonsiepe (2011), this paper discusses the projetual methodology in developing footwear for people with special needs from the case study of a child with Proteus Syndrome. In order to report the difficulties of the user in finding the proper footwear, as a result it was found, there was a predominance of the artisan work relative to designer work in the projection of special shoes in Brazil.
\end{abstract} Brasil.

Palavras Chave: Design. Moda. Calçados. Portadores de necessidades especiais.

Keywords: Design. Fashion. Shoes. People with special needs. 


\section{INTRODUC̣ÃO}

O presente artigo procura buscar a relevância do design, cuja noção equivocada apresenta-nos arraigada na mente de consumidores, profissionais e empresas da área.

Por essa noção incorreta, entende-se a palavra design simplesmente como a aparência do produto final, no entanto, como pontuado por Maldonado (1958), ela é somente um dos aspectos, entre muitos, com os quais um designer deve se preocupar, sendo este nem o mais importante e nem o mais influente num projeto, pois também devem ser planejados a engenharia, a produção, a economia e os aspectos simbólicos.

Com o intuito de resgatar os valores e processos esquecidos deste termo, a pesquisa parte da definição de design sugerida por Bonsiepe (2011), como um "humanismo projetual":

O humanismo projetual seria o exercício das capacidades projetuais para interpretar as necessidades de grupos sociais e elaborar propostas viáveis, emancipatórias, em forma de artefatos instrumentais e artefatos semióticos. Por que emancipatórias? Porque humanismo implica a redução da dominação e, no caso do design, atenção também aos excluídos, aos discriminados [...], ou seja, a maioria da população deste planeta. (BONSIEPE, 2011, p. 21).

Para experimentar a grandiosidade desta definição, o artigo aborda o estudo de caso de uma criança portadora da Síndrome de Proteus, com o objetivo de relatar as dificuldades encontradas na busca por um calçado que atenda suas necessidades, a encante e a faça sentir-se bem, além de mostrar que o designer pode desempenhar um papel mais adequado em casos tão específicos como esse.

A partir deste estudo, a pesquisa discute a metodologia de design, o processo de fabricação artesanal e a própria moda, apresentando e comparando a metodologia proposta por Menezes e Silva (2009) para o setor calçadista e a metodologia utilizada pelo professor e artesão, Ordalino Vasconcelos, que desenvolveu os calçados para a criança e ensinou o oficio à mãe da portadora, para que ela pudesse dar continuidade a esse trabalho.

\section{Estudo de caso $^{1}$}

1 Entrevista realizada com Andréa Domingues (mãe da criança portadora da Síndrome 
A criança de doze anos, do sexo feminino, foi diagnosticada ao nascimento como portadora de uma síndrome denominada "Proteus". Esta síndrome, descrita pela primeira vez em 1979, promove o crescimento desordenado das partes "moles" do corpo, como os tecidos conjuntivo, muscular, epitelial e adiposo, além de ser considerada rara e ainda de origem desconhecida (GONTIJO et al., 2001).

Visualmente, a principal característica apresentada por esta síndrome é o gigantismo de membros que, no caso da criança, se manifesta nos membros inferiores (pés e pernas) e superiores (mãos). A parte cerebral da portadora (estrutura e função) mantém-se preservada, bem como a parte óssea, sendo seu tamanho adequado à idade.

De acordo com a ergonomia física, definida por lida (2005, p.3), como o estudo que "ocupa-se das características da anatomia humana, antropometria, fisiologia e biomecânica, relacionadas à atividade física", pode-se realizar uma análise mais aprofundada dos pés da criança.

Dessa forma, pela observação anatômica, a portadora não apresenta dedos, unhas, nem plantas dos pés (figura 1). A visão fisiológica mostra que seus pés preservam toda capacidade funcional. A análise biomecânica aponta para os mesmos movimentos de uma pessoa sem necessidades específicas, sendo assim, a criança consegue se locomover normalmente, mesmo que pequenas distâncias. E pelo olhar antropométrico seus pés vem demonstrando aumento contínuo do volume, característica própria da síndrome, como já mencionado.

Figura 1 - Imagem externa do pé direito e imagem interna do pé esquerdo (respectivamente) da criança, gerada em 2D pela ferramenta FootScan.

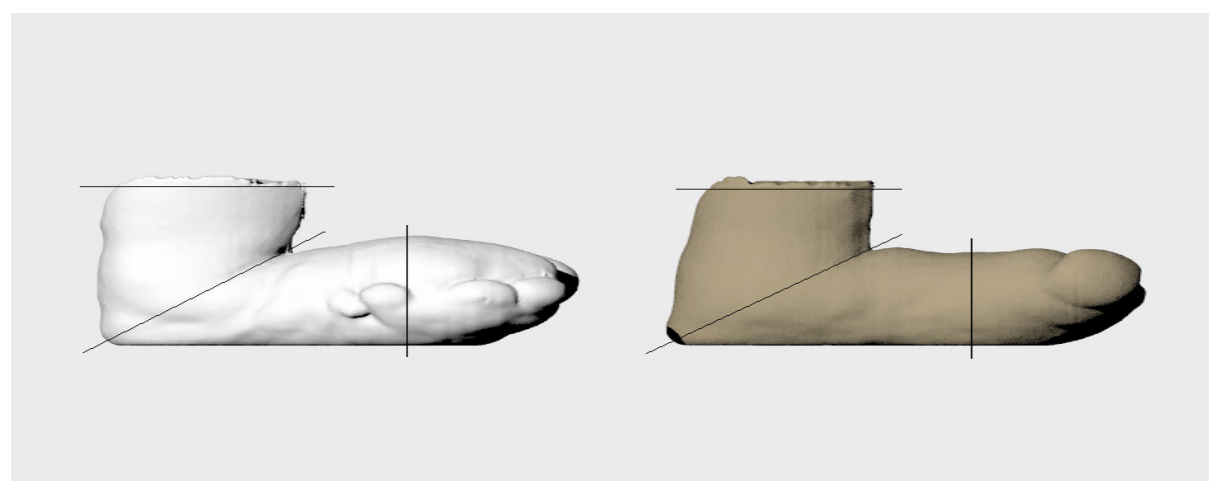

Fonte: Acervo da família da portadora.

Outra característica marcante que pode ser observada na figura 1 é a assimetria dos membros inferiores. Os pés, assim como todos os membros do corpo de um indivíduo não portador de necessidades especiais, apresentam uma de Proteus), em 23 de abril de 2012, via email. 
simetria axial, ou seja, aquela que após o estabelecimento de um determinado eixo, a imagem passa a ser espelhada. No entanto, os pés esquerdo e direito da criança, apresentam ausência desta simetria. Mesmo com a ilustração de partes diferentes (comparação entre lado direito interno e lado esquerdo externo), a desigualdade torna-se evidente quando comparadas: as alturas dos pés e as larguras dos tornozelos.

Todos esses aspectos visuais dos pés da criança apontam para uma discussão estética maior em relação a deformação desses membros inferiores. A beleza, que geralmente está associada à simetria, àquilo que é agradável aos olhos, e a feiura, que em regra é associada à assimetria, podem ser percebidas com um novo caráter no presente estudo de caso. Segundo a visão de Eco (2007, p. 16), muitas vezes o que é incomum pode assumir um papel mais admirável em relação ao belo:

Mas é justamente quando passa das definições abstratas para uma fenomenologia das várias encarnações do feio que ele nos faz entrever uma espécie de "autonomia do feio", que o transforma em algo bem mais rico e complexo que uma série de simples negações das várias formas da beleza

Mesmo assim, este caso demonstra como a sociedade ainda se revela não preparada para conviver com diferentes tipos de beleza. Essas deformações, promovidas por Síndrome de Proteus, ou advindas de outras doenças como a Filariose Bancroftiana ${ }^{2}$, popularmente conhecida como "elefantíase", implicam numa série de fatores cognitivos, que podem afetar o paciente e sua família, como é o caso da exclusão social.

Em termos de preocupação sobre a interação de crianças portadoras de Síndrome de Proteus com o meio, Cohen (2005, p. 51) alerta:

\begin{abstract}
Pais e pacientes afetados normalmente relatam sentimentos isolados por causa da raridade do problema e do estigma social em apresentarem uma condição de desfiguração progressiva. Reações inadequadas de outros podem ser muito dolorosas para as crianças e seus pais.
\end{abstract}

Nessas condições, a mãe da paciente relata que a filha não apresenta vergonha em relação a suas diferenças e há grande inclusão entre os amigos da escola (figura 2).

2 Doença parasitária que pode provocar deformações em membros, testículos e seios. 
Figura 2 - Imagem de brincadeira adolescente entre a portadora e as amigas da escola, demonstrando a inclusão social entre a criança e o meio.

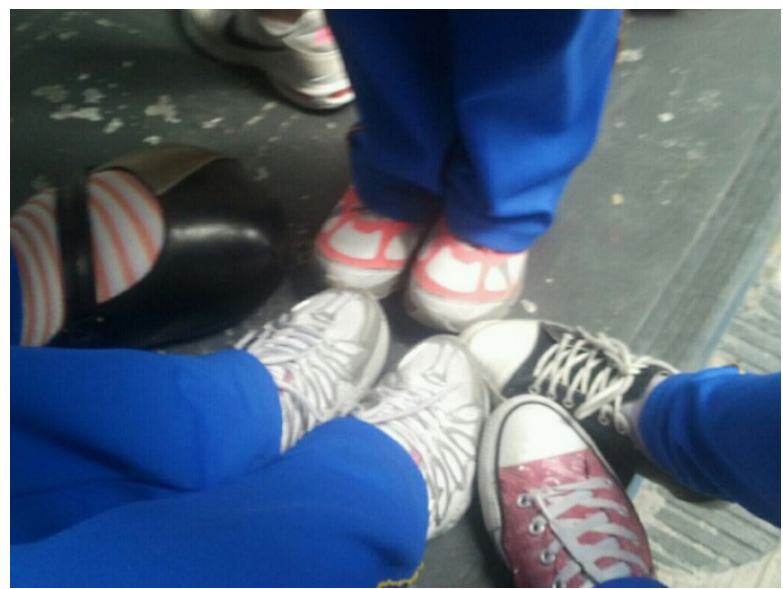

Fonte: Acervo da família da portadora.

Ainda assim, existe um outro tipo de exclusão que advém da moda. Neste caso, Cortella (2013, p.118) aponta que "[...] há nela um feitiço muito poderoso, mescla de arte e técnica, que encanta, agride, acolhe, retrai, anula e enfei".

Hoje aos doze anos, a criança possui uma vida ativa. Anda, dança, nada, estuda, é vaidosa e cada vez mais passa a manifestar seu poder de escolha em relação ao vestuário, principalmente com calçados.

Um dos modelos de maior desejo da criança é o icônico tênis All-Star ${ }^{\circledR}$, criado nos Estados Unidos, em 1917 (DESIGN, 2010). Isto posto, o estilo pessoal de qualquer indivíduo também pode ser interpretado como a forma com que este deseja ser visto e reconhecido pelo meio:

\begin{abstract}
A aparência pode ser gerenciada através do vestir, não só no sentido de esconder, mas também compensar as diferenças visíveis. [...] ao se vestir elegantemente, uma pessoa com deficiência física pode focar a atenção para o seu estilo pessoal, ao invés de sua visível diferença física (HALL; ORZADA, 2013, p.25).
\end{abstract}

Esse argumento vai de encontro ao relato da mãe da criança, que questiona a democracia da moda, de acordo com a dificuldade em encontrar calçados que atendam sua filha tanto no sentido ergonômico, quanto estético, que manifestem seu estilo pessoal e consequentemente beneficiem seu estado emocional.

\title{
A busca pelo calçado adequado
}


O primeiro calçado da criança foi desenvolvido no Lar Escola São Francisco, centro de reabilitação médica que atende pessoas com deficiência física e mobilidade reduzida em qualquer idade. Essa instituição possui oficina ortopédica que produz diversos produtos, inclusive calçados, que auxiliam a locomoção desses indivíduos (LAR ESCOLA SÃO FRANCISCO, 2012).

A partir deste primeiro modelo, a mãe da criança conseguiu com que outros fossem feitos, mesmo assim, os sapatos foram sempre uma luta. Quando ela chegava com a filha nas casas ortopédicas para confeccionar um calçado sob medida, as pessoas ficavam assustadas e recusavam o desafio. Dessa forma, nenhuma casa ortopédica se disponibilizava a fazer os calçados, mesmo com laudo médico dizendo que não havia necessidade de correção ortopédica, apenas a confecção no formato do pé da criança. Devido a estes fatores, a portadora já havia completado um ano de idade e só andava de meias.

As angústias da mãe sempre foram alto valor de confecção e o tempo de espera pelo calçado. Outro incomodo que surgiu com o tempo foi em relação aos modelos: muito parecidos, sem nenhum detalhe ou atrativo e confeccionados em cores restritas (brancos, pretos e beges), pouco encantadoras para uma criança. Dessa forma, aos poucos a própria família adaptou alguns modelos decorando com flores e alguns apliques, chegando também a desenvolver alguns modelos em crochê e pano (figura 3).

Figura 3 - Imagem dos calçados da criança.

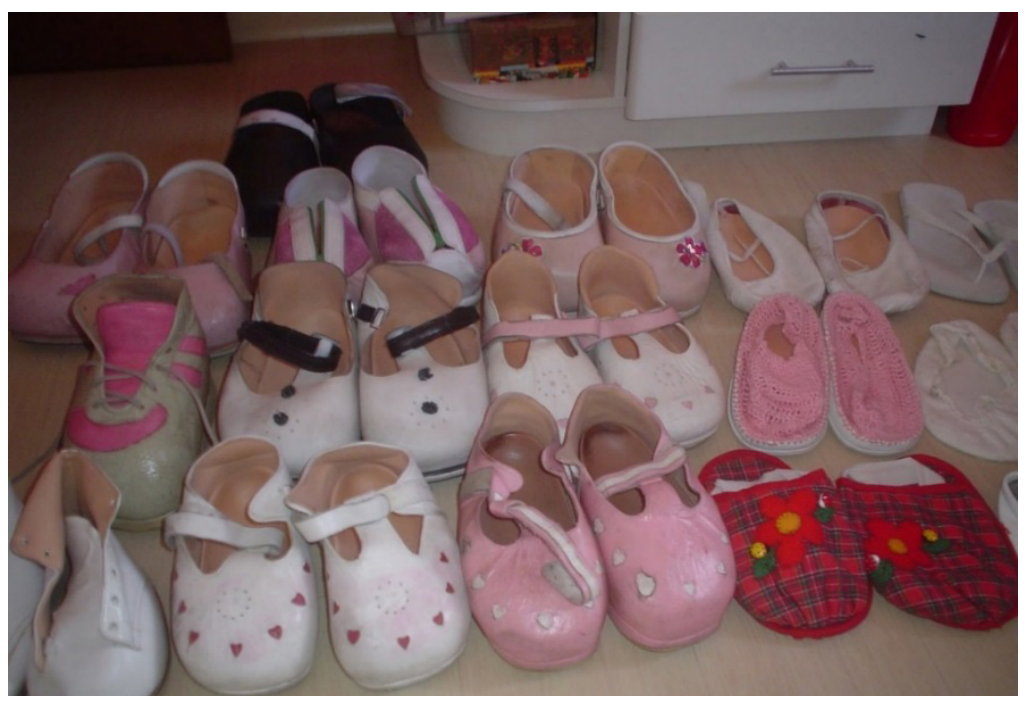

Fonte: Acervo da família da portadora.

Alguns anos depois, a família procurou o IBTeC (Instituto Brasileiro de Tecnologia do Couro, Calçado e Artefatos), em Novo Hamburgo, Rio Grande do Sul. O Instituto, que foi criado com o objetivo de disponibilizar as indústrias do setor um local para desenvolvimento de pesquisas e novas tecnologias, se 
mostrou solicito em ajudar a criança (IBTEC, 2012).

No IBTeC, uma equipe iniciou uma metodologia projetual antes da confecção do calçado. Primeiro foi desenvolvido um desenho virtual em 2D a partir da imagem do perfil dos pés da portadora, gerada pela ferramenta FootScan ${ }^{3}$ e logo depois foi confeccionado um tênis com base nas medidas coletadas pela mesma ferramenta.

Pelo acelerado crescimento dos pés da criança, o calçado já estava apertado quando chegou às mãos da família, mesmo assim, a metodologia de projeto proposta pelo IBTeC foi notória, demonstrando que somente com metodologias e ferramentas adequadas seria possível alcançar os resultados desejáveis (figura 4).

Figura 4 - Imagem do modelo de tênis desenvolvido pelo IBTeC.

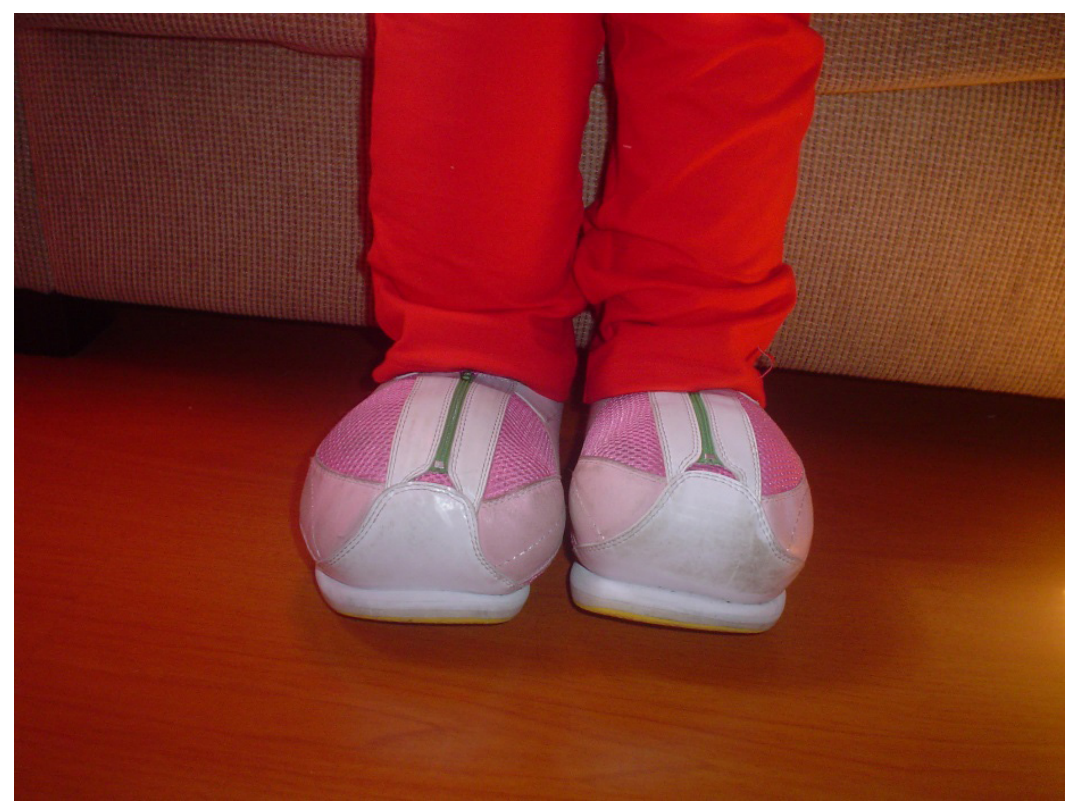

Fonte: Acervo da família da portadora.

A família recorreu então a uma pequena fábrica de calçados, disposta em ajudar, mas a dificuldade estava na disponibilidade de tempo desta empresa, que não conseguiria parar sua produção para desenvolver um calçado de acordo com o modelo e o tempo que a família desejava.

Após diversas tentativas em pedir auxílio a casas ortopédicas, centros tecnológicos de desenvolvimento de calçados e oficinas de sapatos, a mãe da portadora procurou o SENAI (Serviço Nacional de Aprendizagem Industrial), localizado no bairro do Ipiranga, na cidade de São Paulo. Esta unidade do SENAI, tem como especialidade a formação de profissionais para trabalhar com artefatos em couro e afins (SENAI, 2012).

3 Tecnologia de escaneamento digital 3D para os pés. 
Nessa escola, a mãe da criança realizou os cursos de Confeccionador Manual de Cabedais e Modelagem de Cabedais com o intuito de começar a desenvolver calçados para a própria filha. $O$ ingresso nestes cursos proporcionaram o encontro e a aproximação com Professor Ordalino Vasconcelos, sapateiro artesão há quase sessenta anos. Senhor Ordalino, mais conhecido como Professor Lino, se prontificou em ajudar à pequena menina. Desde então, com aplicação de uma metodologia própria, em menos de cinco meses, a portadora ganhou dois calçados, um recorde para a família.

\section{A metodologia do Professor Lino 4}

Para o desenvolvimento dos calçados da criança, foram adotadas etapas fundamentais, informalmente estabelecidas pelo Professor Lino. Dentre as etapas de criação e desenvolvimento dos calçados, podem ser destacadas: a análise do perfil da criança, bem como sua idade e seus desejos de consumo, a elaboração de uma planta do pé e adaptação da primeira fôrma de madeira que já havia sido criada (figura 5).

Figura 5 - Imagens da fôrma de madeira e encaixe para planta do pé adaptados pelo Professor Lino.

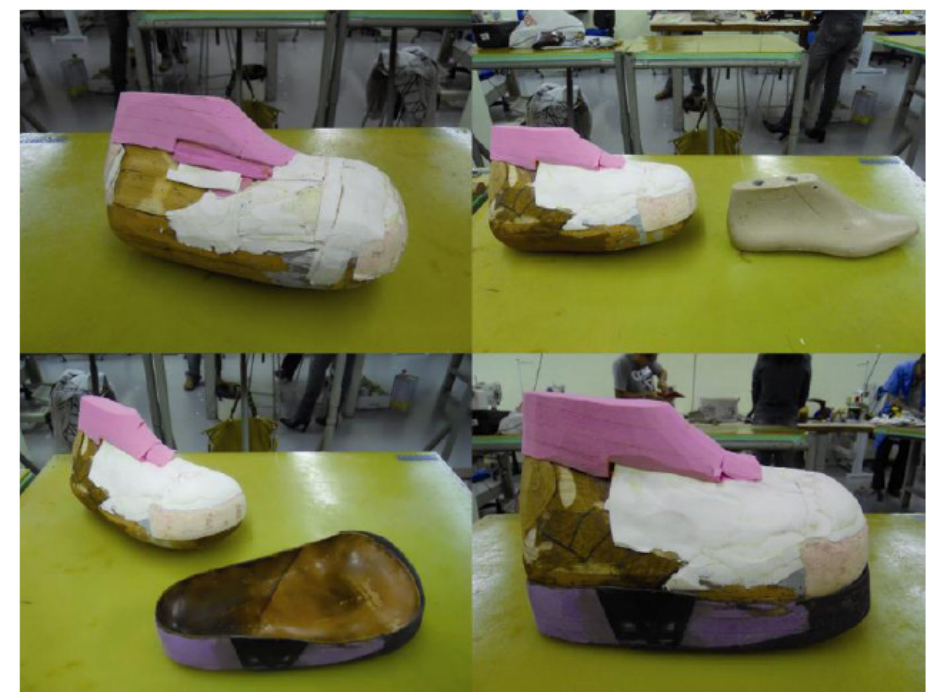

Fonte: Acervo da família da portadora.

As etapas elaboradas pelo Professor Lino vão ao encontro com a metodologia sugerida por Menezes e Silva (2009), baseada em um estudo realizado com os departamentos de criação de fábricas de calçados infantis na cidade de Birigui, interior do Estado de São Paulo, e em metodologias projetuais apresentadas aos alunos dos cursos de design industrial presentes no mesmo

4 Entrevista realizada com Ordalino Vasconcelos (Professor Lino), em 19 de abril de 2012, na cidade de São Paulo, com 47 minutos de duração. 
Estado.

A metodologia direcionada à designers de empresas fabricantes de calçado com produção em série, proposta por Menezes e Silva (2009), é aqui apresentada, adaptada e comparada aos processos de confecção manual elaborados pelo Professor Lino, de acordo com a tabela 1 (planejamento) e tabela 2 (desenvolvimento).

Tabela 1- Planejamento dos calçados elaborados pelo Prof. Lino em 2012 sob a metodologia de Menezes e Silva (2009).

\begin{tabular}{|c|c|}
\hline \multicolumn{2}{|c|}{ Planejamento/Identificação do problema } \\
\hline Menezes e Silva (2009) & Professor Lino/SENAI (2012) \\
\hline $\begin{array}{l}\text { a) Definição do produto/o que se quer } \\
\text { produzir: modelo que se pretende } \\
\text { desenvolver para restrição do campo de } \\
\text { atuação. Busca por informações que lhe } \\
\text { serão úteis. }\end{array}$ & $\begin{array}{l}\text { a) Produtos a serem confeccionados: } \\
\text { um tênis e uma bota. Professor Lino } \\
\text { busca tendências/referências em revis- } \\
\text { tas e vitrines de lojas. }\end{array}$ \\
\hline $\begin{array}{l}\text { b) Informações do público-alvo: com o } \\
\text { modelo definido, o designer deverá saber } \\
\text { qual é o público a que se destina esse } \\
\text { produto, bem como identificar as carac- } \\
\text { terísticas dessa população, seus ansei- } \\
\text { os, suas características e costumes. }\end{array}$ & $\begin{array}{l}\text { b) Público-alvo: criança de doze anos, } \\
\text { sexo feminino, portadora da síndrome } \\
\text { de Proteus, com presença de gigantismo } \\
\text { e deformidades nos membros inferiores. } \\
\text { É ativa e quer ter o poder e o prazer de } \\
\text { escolha do que usar/vestir de acordo } \\
\text { com sua idade. }\end{array}$ \\
\hline $\begin{array}{l}\text { c) Coleta de dados sobre materiais no } \\
\text { mercado externo e o nacional: esses } \\
\text { dados devem se referir às informações } \\
\text { técnicas da matéria-prima, bem como } \\
\text { à distância entre o produtor desta e a } \\
\text { fábrica. }\end{array}$ & $\begin{array}{l}\text { c) Coleta de dados de materiais para a } \\
\text { confecção: couros coloridos, linhas de } \\
\text { costura macias, palmilhas em E.V.A., } \\
\text { solados de couro e solados em E.V.A., } \\
\text { cadarços coloridos e macios, ilhoses, } \\
\text { fivelas, velcros, etc. }\end{array}$ \\
\hline
\end{tabular}


d) Análise de dados ergonômicos, a partir de informações do público-alvo: nesse caso, o designer deverá conhecer as características fisiológicas do pé da população que utilizará esse produto, utilizando a fôrma correta para produzir o modelo, observando as características dos materiais de acordo com o fabricante da matéria-prima, para não prejudicar a boa utilização do calçado, provocando dores, calos e incômodos em geral, que afetam o bem-estar do usuário.

e) Análise dos produtos concorrentes: conhecer o mercado é um dos passos para o designer tentar localizar possíveis falhas, fazendo com que esses detalhes possam se tornar oportunidades para ganhar mercado. Ele pode também definir o tamanho do mercado que se pretende alcançar.

f) Definição dos requisitos para o novo modelo que se quer produzir: após saber o modelo a ser desenvolvido, conhecer o público-alvo, o mercado concorrente e as tendências da moda, devem-se listar todos esses itens como requisitos de projeto, norteando a produção dos novos modelos. d) A paciente possui deformidade nos pés, o que não permite com que ande longas distâncias sem que provoque rápido cansaço físico. Seu pé, devido à síndrome, apresenta um inchaço por parte do crescimento das partes moles (tecido epitelial, muscular e conjuntivo) e ausência de dedos, unhas e planta dos pés. Com características tão delicadas, seus pés necessitam de formas próprias e modelagens bem planejadas, que não os agridam.

e) Prof. Lino verificou falhas nos sapatos produzidos por outros profissionais, a partir de uma fôrma de madeira projetada com antigas medidas da criança: sapatos pesados, que impediam a locomoção, e confeccionados em material sintético, não permitindo a respiração dos pés.

f) A portadora necessita de calçados de fácil calce, em couro, permitindo a transpiração, sem forro para maior conforto, sem muitas costuras, modelagens bem planejadas para não machucar os pés, materiais leves, que permitam sua locomoção, cores vibrantes de acordo com sua idade e que junto com a modelagem criem certa ilusão de ótica que proporcionem uma falsa diminuição dos pés. Outra preocupação também nesta etapa é a elaboração de uma base para criar uma falsa "planta do pé" auxiliando sua locomoção. 


\begin{tabular}{|l|l|}
\hline g) Interação entre os requisitos: & g) Diálogos necessários entre o médico, \\
essa interação deve acontecer em & a mãe, a criança e o Prof. Lino para \\
reuniões com designers, modelistas, & melhor entendimento das necessidades \\
estilistas, gerentes e técnicos, que & e restrições da usuária para que haja \\
poderão opinar quanto ao modo de & sucesso no projeto do calçado.
\end{tabular}

abordar todos os itens técnicos.

Fonte: Menezes e Silva (2009).

Tabela 2 - Desenvolvimento dos calçados elaborados pelo Prof. Lino em 2012 sob a metodologia de Menezes e Silva (2009).

\begin{tabular}{|c|c|}
\hline \multicolumn{2}{|c|}{ Desenvolvimento de produto } \\
\hline Menezes e Silva (2009) & Professor Lino/SENAI (2012) \\
\hline $\begin{array}{l}\text { a) Definição de todo o processo } \\
\text { para buscar a solução: trata-se da } \\
\text { definição de qual técnica de geração de } \\
\text { alternativas será utilizada. Aqui cabe } \\
\text { ao designer introduzir na indústria a } \\
\text { necessidade de trabalhar uma técnica } \\
\text { de criação de alternativas que se } \\
\text { apresente como eficaz, fazendo com } \\
\text { que outros designers possam seguir } \\
\text { seu exemplo, melhorando sempre a } \\
\text { técnica utilizada. Geralmente, essa } \\
\text { técnica se resume em alguns desenhos/ } \\
\text { esboços e na elaboração do modelo } \\
\text { diretamente na forma do calçado, } \\
\text { coberta pela fita adesiva que servirá } \\
\text { para a modelagem do calçado. }\end{array}$ & $\begin{array}{l}\text { a) A partir de uma fôrma de madeira, já } \\
\text { desenvolvida por outros profissionais, o } \\
\text { Prof. Lino foi a adaptando, conforme o } \\
\text { crescimento do pé da criança. Ele faz as } \\
\text { medições diretamente no pé da usuária } \\
\text { e aumenta o volume da fôrma com } \\
\text { placas de E.V.A. que, posteriormente, } \\
\text { são lixadas, remodelando a fôrma. } \\
\text { Dessa forma, com as novas medidas, } \\
\text { a fôrma é encapada com fita } \\
\text { adesiva para se desenhar e tirar } \\
\text { o molde do modelo escolhido. }\end{array}$ \\
\hline
\end{tabular}




\section{b) Utilização de técnicas de criatividade para obtenção das ideias: normalmente não se trabalha nenhuma técnica conhecendo-a com nome e procedimentos definidos. Esse processo inicia-se com a produção de alternativas com simples esboços, depois se fazem desenhos mais apurados com o auxílio do computador. Alguns designers partem diretamente para a fabricação de protótipos denominados "modelos" sem antes fazerem estudos utilizando desenhos ou softwares, apenas desenhando no corpo da fôrma.}

c) Análise crítica e avaliação a partir da modelagem técnica das alternativas produzidas com os modelos, observando a viabilidade da fabricação: geralmente a produção de alternativas é avaliada em reunião com gerentes, técnicos e responsáveis pela aprovação, definindo qual será o produto escolhido para ser fabricado e que os vendedores poderão apresentar aos lojistas.

d) Definição da tecnologia a ser empregada, bem como o estudo da mão-de-obra para a fabricação: os responsáveis pela produção deverão definir quais máquinas/processos serão utilizados, bem como se há a necessidade de fabricar alguma faca de corte específica para aquele modelo, ou outro processo que deverá ser incrementado à linha de produção. b) Nesta etapa, a utilização de um software não se aplica aos procedimentos do Prof. Lino. O modelo é desenhado diretamente na fôrma, coberta com fita adesiva, de onde será tirada a modelagem e confeccionará o protótipo para o primeiro teste de calce.

c) Esta etapa não se aplica ao caso. 0 modelo é predefinido e projetado de acordo com as necessidades da usuária. A aprovação do modelo ocorre por meio do teste de calce diretamente com a consumidora final. Assim, há facilidade na comunicação artesão/consumidor sobre aspectos técnicos do calçado.

d) Confecção manual/artesanal corte simples do couro utilizando facas adequadas; processo de escarnir/ chanfrar o couro (escamação da carne para a preparação da dobra); processo de pesponto com uso de cola forte para a dobra e pouca costura em máquina reta; processo de montagem junto à fôrma; processo de pranchamento com uso de cola a base de P.V.C. para fixação do solado e processo de acabamento.

Fonte: Menezes e Silva (2009).

Bonsiepe (2011, p.35-36) explica esta falta de interação e a origem do design, relatando que: 
tradição forte porque o ensino do design surgiu de uma tradição artesanal, com uma profunda desconfiança contra tudo o que é teórico.

Menezes e Silva (2009) também analisam essa miopia, e apontam o problema atual como falta de interação entre as indústrias e as universidades:

Consideramos ainda a necessidade de maior intercâmbio entre indústria e universidade por meio da integração das metodologias utilizadas em cada uma delas, de forma a permitir uma melhor formação do futuro designer e aumentar sua participação no processo de produção da fábrica (MENEZES, SILVA, 2009, p. 129).

Comparando os resultados obtidos antes de encontrar o Professor Lino com a metodologia aplicada por ele posteriormente, fica mais evidente como a teoria e a prática do design estão distantes. Em casos específicos como esse, a atenção deve ser redobrada em relação às necessidades do portador de deficiência. Quando se encontra a metodologia, a técnica e o conforto observam-se a ausência da preocupação estética e vice e versa.

As metodologias aqui apresentadas revelam como a teoria e a prática do design de produtos, no caso, calçados, devem ser seguidas para se obter o resultado esperado como no caso apresentado. Mas é também de relevância lembrar que existem muito outros casos específicos para elaboração de calçados adequados, como um portador de Filariose Bancroftiana, já citado anteriormente, ou até mesmo um diabético:

\footnotetext{
O portador de elefantíase dos membros inferiores não pode usar calçados comuns [...]. Apenas o paciente sabe a quantidade de energia, de motivação e o tempo gasto para encontrar os sapateiros da periferia que tenham a criatividade de adaptar o calçado à sua deformidade. Precisa, então, de ajuda extra nesse sentido, inclusive para ser esclarecido de como deve informar as suas necessidades, tão pessoais, ao sapateiro local (DREYER, MATTOS, 2006).
}

Portanto, em casos como esses, nota-se ainda a forte imagem do sapateiro/artesão, bem como o seu trabalho artesanal, em relação à teoria e prática projetual do designer de produtos no mercado de calçados. 


\section{CONSIDERAC̄ÕES FINAIS}

Em toda essa jornada a mãe da criança observou a lacuna existente entre teoria e prática do design, relatando que a maioria dos produtos voltados para os deficientes não atentam para o lado da aparência e que as necessidades de conforto do deficiente são prioridade, mas o prazer de se vestir e calçar bem, também faz parte da qualidade de vida do indivíduo.

Por isso o papel do designer em um projeto é unir a teoria e a prática, buscar o equilíbrio entre os "aspectos técnicos" e os "aspectos semânticos" dos objetos e ainda "intervir na realidade" e "superar as dificuldades" como propõe Bonsiepe (2011).

Neste caso, testemunha-se também, a predominância do artesão, e a sua informalidade projetual em relação ao papel do designer que, enquanto não entender o real significado da sua profissão, deixa de contribuir com sua classe, ao próximo e consigo mesmo em termos de crescimento e bagagem profissional.

Menezes e Silva (2009) indicam que o profissional deve se qualificar em suas atividades e áreas afins para conhecerem detalhes que contribuam cada vez mais para a "linguagem da concepção e fabricação".

Dessa forma, o lado humano do design precisa também ser estendido a outros objetos de uso diário, como carros, bicicletas, bolsas, computadores, entre outros, lembrando que há mercado para esses e outros tipos de portadores de necessidades especiais. Para preencher esse aparente vazio existente entre teoria e prática de design e ressaltar a inclusão social relatada neste trabalho, aqui se propõe o surgimento de cadeiras específicas nos cursos de design que abordem o desenvolvimento de produtos voltados a este público.

O "humanismo projetual" portanto, necessita ser o ponto de partida na vida de um designer, para que haja a reintegração entre teoria e prática de projeto e para que os profissionais da área não percam sua credibilidade no mercado e que, perante aos usuários, o produto em si adquira importância decisiva em suas vidas e em seu bem-estar.

\section{REFERÊNCIAS}

BONSIEPE, Gui. Design, cultura e sociedade. São Paulo: Blucher, 2011. 
Journal of Medical Genetics. 2005.Disponível em:<http://www.proteussyndrome.org/html/reference/fulltext.pdf>. Acesso em: 22 abr. 2012.

CORTELLA, Mario Sergio. Não se desespere: provocações filosóficas. 3.ed. Petrópolis: Vozes, 2013.

DESIGN Museum. Cinquenta sapatos que mudaram o mundo. Belo Horizonte: Autêntica Editora, 2010.

DOMINGUES, Andréa. Estudo de caso Síndrome de Proteus. [mensagem pessoal]. Mensagem recebida por <andrea_domingues@uol.com.br> em 23 de abril de 2012.

DREYER, Gerusa; MATTOS, Denise. A filariose bancroftiana: uma perspectiva psicossocial e política para os profissionais da saúde. Revista Panamericana de Infectologia, v. 8, n. 2, p. 35-39, 2006. Disponível em: <http://www.amaurycoutinho.org.br/english/publication/82.pdf>. Acesso em: 19 abr. 2012.

ECO, Umberto. História da feiura. Rio de Janeiro: Record, 2007.

GONTIJO, Bernardo; PEREIRA, Luciana Baptista; SILVA, Cláudia Márcia de Resende; VIEIRA, N.R.N. Síndrome de Proteus: relato de caso. Anais brasileiros de Dermatologia, Rio de Janeiro, v. 76, n. 2, p.201-208, mar./ abr. 2001.

HALL, Martha L.; ORZADA, Belinda T. Expressive Prostheses: Meaning and Significance. Fashion Practice, v. 5, p.9-32, 2013.

IBTEC. Institucional. Disponível em:<http://www.

ibtec.org.br/internas/index.php?request =tamp_

one\&group=1\&session=Apresenta\%E7\%E3o\&id=34>. Acesso em: 22 abr. 2012.

IIDA, Itiro. Ergonomia: Projeto e Produção. 2. ed. São Paulo: Edgard Blücher, 2005.

LAR ESCOLA SÃO FRANCISCO. Instituição. Disponível em:<http:// larescola.com.br/wp/ instituicao/>. Acesso em: 22 abr. 2012.

MALDONADO, Tomas. Neue Entwicklungen in der Industrie und die Ausbildung des Produktgestalters. In: ulm, Zeitschrift der Hochschule für Gestaltung, n. 2, [s.l.], 1958. 
MENEZES, Marizilda dos Santos; SILVA, Fernando José. Design e metodologia nas indústrias de calçados. In: MENEZES, Marizilda dos Santos; PASCHOARELLI, Luis Carlos (Org.). Design e planejamento: aspectos tecnológicos. São Paulo: Cultura Acadêmica, 2009. p. 129-141.

ORDALINO, Vasconcelos. Desenvolvimento de calçados para portadora de Síndrome de Proteus. São Paulo: SENAI, 2012. Entrevista com duração de $47 \mathrm{~min}$.

SENAI. Perfil Institucional. Disponível em:<http://www.sp.senai.br/ artefatosdecouro/Webforms/Interna.aspx?secao_id=4>. Acesso em: 25 abr. 2012.

Recebido em:

Aceito em: 